\title{
The Effect of Restructuring on Unemployment
}

\author{
Andrew Figura* \\ Board of Governors of the Federal Reserve System \\ October 27, 2003
}

JEL Classifications: E24, E32, J64

Keywords: Restructuring, Unemployment, Job Flows

\begin{abstract}
This paper finds that the permanent job losses associated with industrial restructuring have significantly boosted the variance of unemployment, causing it to rise much higher in recessions than it would have without cyclically correlated restructuring. Moreover, the influence of restructuring has increased noticeably in the 1980s and 1990s, acting to increase economic instability at a time when other factors were operating to reduce it.
\end{abstract}

*Mail Stop 80, Board of Governors of the Federal Reserve System, Washington, DC 20551. Email: jfigura@frb.gov. The views presented are solely those of the author and do not necessarily represent those of the Federal Reserve Board or its staff. I would like to thank the Bruce Fallick, Doug Elmendorf, and Bill Wascher for useful comments. 
This paper finds that changes in employment associated with industrial restructuring have significantly boosted the variance of unemployment, causing it to rise much higher in recessions than it would have without cyclically correlated restructuring. Moreover, the influence of restructuring has increased noticeably in the 1980s and 1990s, acting to increase economic instability at a time when other factors were operating to reduce it. ${ }^{1}$ Three characteristics of restructuring have determined its effect on unemployment. First, restructuring is not characterized by simultaneous permanent job losses in one sector and permanent job gains in another sector within a state. Instead, permanent job creation and permanent job destruction are negatively correlated contemporaneously and at several lags so that an increase in permanent job loss does not lead to new job gains either contemporaneously or in the near future. Second, changes in permanent (or restructuring related) job flows have caused larger movements in unemployment than other employment changes, which suggests that restructuring has predominantly affected workers with low mobility and/or high amounts of industry specific human capital or rents. Finally, it takes workers some time to realize that changes in employment are permanent. This causes unemployment to rise more initially than it would if the permanence of the change were immediately recognized.

\section{Background}

In this paper, restructuring is defined as the destruction and creation of job capital, where job capital comprises the human, physical, and organizational capital underlying particular jobs. Because much of this capital is specific to jobs, plants, or industries (Topel, 1990, Bahk and Gort, 1993, Ramey and Shapiro, 1998), changes in demand or technology that cause the permanent elimination of jobs destroys much of this capital. Conversely, the building of permanent new jobs requires substantial investment in job capital.

An example may help to clarify this idea. Suppose a manufacturer creates jobs to make a new kind of widget. The capital behind these jobs includes: the time spent

1. Papers noting and seeking to explain the decline in the variance of GDP since the early 1980s include McConnell and Perez-Quiros, 2000, Stock and Watson, 2002, and Ahmed, Levin, and Wilson, 2002. 
gathering and analyzing the information needed to decide that producing this new kind of widget would be profitable and to determine the optimal technology to produce them; the relationships established with both suppliers of materials needed to make the widgets and distributors of the widgets; the machines and structures used to produce the widgets; and the hiring and training of workers who operate the widget factory. If, at some point, demand or technology changes so that these widgets are no longer profitable to produce using the acquired technology, then this capital loses much of its value. The decision to no longer produce these widgets and eliminate the jobs involved in their production in essence destroys this capital. Finally, the process of creating and/or destroying this job capital is what I refer to as restructuring. ${ }^{2}$ I assume that restructuring can be identified with permanent job loss or permanent job gains. ${ }^{3}$

Because restructuring entails the destruction of built-up capital, it can have potentially large costs, and it is in part because of these costs that it has garnered so much attention. Much of this attention has focused on restructuring as a cause of unemployment and a cause of rising and persistent unemployment in the last two recessions. This paper attempts to explain what features of restructuring have led it to affect unemployment and then attempts to quantify the importance of restructuring to cyclical movements in unemployment.

This attempt relates to some previous research. One strand of related literature has focused on the reallocation of workers across industries. Lilien, 1982, attempted to measure the fraction of cyclical movements in unemployment attributable to reallocation shocks (shocks to the optimal distribution of resources across production units) and the fraction attributable to aggregate demand shocks. Abraham and Katz, 1986, criticized his measure of reallocation, showing that its cyclical movements likely derived from the different responses of sectors to aggregate shocks. Since then, much of the literature has tried to devise better methods to distinguish between reallocation shocks and aggregate

2. The above process is often referred to as creative destruction, and is one process by which new technology becomes embodied in productive assets. New job capital is also created when firms upgrade technology at existing plants without creating or destroying jobs.

3. Sufficient conditions for this assumption are that restructuring occurs across and not within plants or industries and that restructuring is caused by low frequency changes in relative demand or technology. Figura, 2003, shows that other less restrictive conditions would also be sufficient. 
shocks as causes of cyclical movements in unemployment, Brainard and Cutler, 1993, Campbell and Kuttner, 1996, Loungani, Rush and Tave, 1990.

This paper focuses on a different concern. Because restructuring is distinct from other types of changes in labor demand, with different costs and potentially different optimal public policy responses, understanding its magnitude, how it varies with the cycle and how workers affected by it respond are important questions, regardless of whether cyclical movements in restructuring are exogenous or driven by aggregate demand shocks. Instead of trying to discern the origins of cyclical movements in restructuring, this paper asks the following questions: has unemployment caused by restructuring been different than unemployment caused by temporary demand or supply shocks, what is the share of aggregate unemployment changes due to restructuring, and has this share changed over time.

The correlation between restructuring and the business cycle prevents identification of both the causes and effects of restructuring at the aggregate level. In an attempt to identify the effects, I follow another strain in the literature, which exploits heterogeneity in regional, state, and local labor markets. ${ }^{4}$ Though restructuring related job flows are correlated with the cycle, they occur at differing magnitudes at different times in different states. For example, Michigan in the early 1980s had above average restructuring related to problems in the domestic auto industry, while California in the early 1990s had a relatively large amount of restructuring related to defense cutbacks following the end of the Cold War. This variation helps to identify the effect of restructuring on unemployment.

Some previous papers have looked at the effects of different types of shocks on local unemployment (Holzer, 1991, Bound and Holzer, 2000, and Loungani and Bharat, 1997), while other papers have examined local labor force responses to different types of shocks (Bound and Holzer, 2000, and Topel, 1986). However, none have measured the effects of industrial restructuring on unemployment, examined how labor force responses to industrial restructuring differ from other types of labor demand shocks, nor looked at

4. Hall, 1970, looked at why local labor market unemployment rates differ persistently. Marsten, 1985, Bartik, 1991, and Gabriel, Shack-Marquez and Wascher, 1991, among others, examine how local unemployment rates adjust to demand shocks. 
the cyclical variation of industrial restructuring and how its influence on unemployment has changed over time. ${ }^{5}$

\section{Modeling Restructuring and Changes in State Unemployment}

\section{Model}

The basic model derives from Lucas and Prescott, 1974. In the model there are many labor market segments, where workers can produce either market or non-market goods. The technology for market output is subject to random shocks, which cause workers to move into and out of unemployment within a labor market segment and to move across labor market segments. ${ }^{6}$ Because longer lasting shocks to market output technology (those related to restructuring) have greater effects on the value of being in a particular labor market, they produce larger movements in the labor force, and as a result, smaller movements in unemployment. However, this prediction can be modified in two ways. First, if workers are initially unsure if a change is long-lasting, the labor force movements caused by restructuring may be delayed. Second, if restructuring tends to affect segments where workers are less mobile or if restructuring is positively correlated among segments where mobility is easiest, the relative effect of restructuring on unemployment becomes ambiguous.

Job market segments are indexed by $i, i=1$ to $M$. There are an infinite number of workers distributed on the interval $[0,1]$ and indexed by $j$. In time period $t$, a worker in segment $i$ can pursue one of three activities: produce market output, $y_{i}$, and be employed, produce non-market output, $h$, or move to a different labor market segment. In the latter two activities, workers are considered to be unemployed.

The technology for market production, $y_{i}$, is

$$
y_{i, t}=f\left(\alpha_{i, t}, e_{i, t}\right)
$$

where $e_{i, t}$ is employment in segment $i$ at time $t$ and $\alpha_{i, t}$ is the parameter governing technology in segment $i$. The market production technology has the following attributes

5. Groshen and Potter (2003) investigate whether restructuring has changed over time.

6. With some minor modifications, which would not affect the main results, shocks could also represent changes in the relative demand for the output of a segment. 


$$
f_{\alpha}\left(\alpha_{i, t}, e_{i, t}\right)>0, f_{e}\left(\alpha_{i, t}, e_{i, t}\right)>0, f_{e e}\left(\alpha_{i, t}, e_{i, t}\right)<0, f_{e a}\left(\alpha_{i, t}, e_{i, t}\right)>0
$$

where subscripts on $f$ denote derivatives.

Non-market production technology is

$$
h=l \chi
$$

Workers must devote their time wholly to market or non-market production

$$
e, l \in(0,1), e+l=1
$$

The labor force in segment $i, l f_{i, t}$, equals the number of workers in segment $i$; employment, $e_{i, t}$, equals the number of workers employed in segment $i$; and unemployment is the difference between the two

$$
l f_{i, t}=\int_{j \in i} j d j, \quad e_{i, t}=\int_{j \in i} e_{j, t} d j, \quad u_{i, t}=l f_{i, t}-e_{i, t}
$$

Utility is linear in the consumption of market and non-market goods.

$$
u\left(y_{i, t}, h\right)=y_{i, t}+h
$$

At the start of period $t$, shocks to each segment's relative technology are realized, and workers in each segment choose whether to remain in the segment or move to another segment. If they remain in the segment, they must choose whether to produce market output and be employed or produce non-market output and be unemployed. If agents choose to move, they must acquire new skills and search for a job. As a result, they must spend a period producing neither market nor non-market output.

First, consider the decision to produce market or non-market output. From (1)(6), workers in a segment will produce market goods until the marginal utility of market production equals the marginal utility of non-market production.

$$
f_{e}\left(\alpha_{i, t}, e_{i, t}\right)=\chi
$$

However, the beginning period labor force may constrain the amount of employment, so that

$$
f_{e}\left(\alpha_{i, t}, e_{i, t}\right)=\operatorname{Max}\left(\chi, f_{e}\left(\alpha_{i, t}, l f_{i, t}\right)\right)
$$


Next, consider the decision whether to remain in segment $i$ or move to another labor market segment. At the beginning of period $t$, the value of remaining in segment $i$, assuming no change in the labor force, is

$$
V^{i, t}\left(\alpha_{i, t}, l f_{i, t-1}\right)=\operatorname{Max}\left(f_{e}\left(\alpha_{i, t}, l f_{i, t-1}\right), \chi\right)+\beta E V^{i, t+1}\left(\alpha_{i, t+1}, l f_{i, t-1}\right)
$$

If workers move they receive $\beta E \operatorname{Max}_{k}\left\{V^{k, t+1}\left(\alpha_{k, t+1}, l f_{k, t-1}\right)\right\}=E \lambda_{t}$.

In equilibrium workers should move to segments with the highest expected future value, and the value of segments which receive new workers should be equal. So for any segment $i$ that receives workers, $i \in R$, the values should be equal and greater than any other segment.

$$
E \lambda_{t}=\beta E V\left(\alpha_{i, t+1}, l f_{i, t}^{*}\right)=\beta E V\left(\alpha_{j, t+1}, l f_{j, t}^{*}\right) \geq \beta E V\left(\alpha_{k, t+1}, l f_{k, t}^{*}\right), \forall i, j \in R, \forall k \notin R
$$

where $l f_{k, t}{ }^{*}$ is the equilibrium value of the labor force in segment $k$ at the end of period $t$, and $\lambda_{t}$ represents the value of moving out of a segment. In equilibrium, the value of being in segment $i$ is

$$
V\left(\alpha_{i, t}, l f_{i, t-1}\right)=\operatorname{Max}\left\{\operatorname{Max}\left(f_{e_{i, t}}\left(\alpha_{i, t}, l f_{i, t-1}\right), \chi\right)+\beta \operatorname{EMin}\left\{V\left(\alpha_{i, t+1}, l f_{i, t}^{*}\right), \lambda_{t}\right\}, \lambda_{t}\right\}
$$

The ability to move across segments insures that there is a floor under the value of being in segment $i$ equal to $E \lambda_{t}$ and a ceiling equal to

$$
\operatorname{Max}\left(\chi, f_{e_{i, t}}\left(\alpha_{i, t}, l f_{i, t}\right)\right)+E \lambda_{t}
$$

Unemployment occurs in segment $k$ when (7) holds and

$$
\chi+\beta E V^{i, t+1}\left(\alpha_{i, t+1}, l f_{i, t}^{*}\right) \geq E \lambda_{t}
$$

or when the segment increases its labor force, $l f_{i, t}^{*}>l f_{i, t-1}^{*}$. In the former case, unemployment occurs because the value of non-market production exceeds the value of market production when the entire labor force is employed, but outside opportunities are not attractive enough for all non-employed workers to leave. In the latter case, workers are unemployed because they must spend a period acquiring skills and searching for jobs when they first enter a labor market segment. 
This model has the feature that given some reasonable assumptions (see proof (i) in Appendix) restructuring occurs in downturns. To see this, suppose that $\alpha_{i}$ has a component common to all segments, and an idiosyncratic component, specific to each segment and independent across segments.

$$
\alpha_{i, t}=\hat{\alpha}_{t}+\tilde{\alpha}_{i, t}
$$

One could think of movements in the common component, $\hat{\alpha}$, as aggregate technology shocks. Given (7) and $f_{\alpha}>0$, workers are more likely to be employed when $\hat{\alpha}$ is high. However, when $\hat{\alpha}$ declines, production of market goods becomes less attractive relative to non-market production and moving across sectors. More formally, at the beginning of a period, agents move out of a segment when the cost, $\operatorname{Max}\left(f_{e_{i, t}}\left(\alpha_{i, t}, l f_{i, t-1}\right), \chi\right)$, is less

than the benefit, $E\left(\lambda_{t}-\beta V^{i, t+1}\left(\alpha_{i, t+1}, l f_{i, t-1}\right)\right)$. Differentiation of these values shows that the cost is more procyclical than the benefit, causing movement across sectors to be countercyclical. If the difference in values between segment $i$ and the best alternative is permanent, then this movement represents restructuring. This implication of the model is similar to Davis and Haltiwanger, 1990, Mortensen and Pissarides, 1994, and Caballero and Hammour, $1996 .^{7}$

Now, consider the effect of long-duration versus short duration changes in demand. Suppose $\alpha$ has natural value $\bar{\alpha}$ and that $\alpha$ can only deviate from this value for specific durations, $n_{1}$ and $n_{2}$, where $n_{1}>n_{2}$. In any period in which $\alpha=\bar{\alpha}$, there is a probability, $\gamma$, that $\alpha$ changes. $\Delta \alpha \sim$ i.i.d. $(0, \sigma)$. With probability $\pi_{y}$ the change is longduration and with probability $\left(1-\pi_{y}\right)$ it is short-duration. For example, if $\alpha_{i, t+1}>\alpha_{i, t}$, and this is a long-term change, then $\alpha_{i, t+1}=\alpha_{i, t+2}=\alpha_{i, t+3}=\ldots=\alpha_{i, t+n_{1}}$ and $\alpha_{i, t+n_{1}+1}=\bar{\alpha}$. Then, assuming that labor force flows occur for both permanent and temporary changes in

7. In Mortensen and Pissarides, 1994, building new job capital is accomplished by job search, while in Caballero and Hammour, 1996, building job capital also entails some sunk costs. As a result, job destruction is countercyclical, while job creation is procyclical. For the present model to match the procyclical nature of job creation, some friction in the job creation process would need to be introduced. 
demand, from $\frac{\partial V^{i, t}}{\partial \alpha_{i, t}}>0$ and equation (11), a long duration change in $\alpha$ will cause a larger movement of the labor force either into or out of segment $i$ then a short duration change in $\alpha$, as in Topel, 1986 (see proof (ii) in the Appendix).

With the existence of unemployment in segment $i$, equation (7) holds, and the change in employment in period $t$ just depends on the change in $\alpha_{\mathrm{i}, \mathrm{t}}$, not its duration. As a result, the change in employment caused by either the short or the long duration movement in $\alpha$ is the same. Then since the change in unemployment in segment $i$ is

$$
\Delta u_{i, t} \approx-\Delta \ln \left(e_{i, t} / l f_{i, t}\right)=\Delta \ln \left(l f_{i, t}\right)-\Delta \ln \left(e_{i, t}\right)
$$

the unemployment rate will change less with a longer duration or permanent change in demand than with a short duration change.

This result can be modified in two ways: first, if agents are uncertain whether a change in $\alpha$ is short-duration, event $s$, or long duration, event $l$; second, if permanent changes tend to affect sectors where it is costly to move or if permanent changes are positively correlated among sectors where mobility is relatively costless.

If agents are uncertain whether a change in $\alpha$ is short-duration or long duration, they may delay movement, and the initial effect of a permanent change may be very close to a non-permanent change in demand. With time, however, as the duration of the change increases, agents will increase their subjective probabilities that the shock is permanent and act accordingly. Given the unconditional probabilities of short duration, $\left(1-\pi_{x}\right)$, and long duration, $\pi_{x}$, employment changes, if the change in $\alpha_{i}$ has lasted $g$ periods, by Bayes' Law, the conditional probability that it is a long-term change is

$$
\operatorname{Pr}\left(\Delta \alpha_{i}=l \mid d=g\right)=\frac{\operatorname{Pr}\left(d=g \mid \Delta \alpha_{i}=l\right) \pi_{x}}{\operatorname{Pr}\left(d=g \mid \Delta \alpha_{i}=s\right)\left(1-\pi_{x}\right)+\operatorname{Pr}\left(d=g\left|\Delta \alpha_{i}=l\right|\right) \pi_{x}}
$$

where $d$ is the duration of $\Delta \alpha_{i}$. If $\frac{\partial \operatorname{Pr}\left(d=g \mid \Delta \alpha_{i}=s\right)}{\partial g}<\frac{\partial \operatorname{Pr}\left(d=g \mid \Delta \alpha_{i}=l\right)}{\partial g}$, then as the duration increases, agents will come to assign more probability weight to a longduration shock. Thus, initially, if workers have relatively little information about the 
duration of a shock, they may respond similarly to short-term and long-term shocks, but over time, as they accumulate knowledge, movements out of the labor force should be greater for long-term shocks (see proof (iii) in the Appendix).

Next, suppose there are fixed costs of moving out of sector $i, C_{i}$. Then equation (11) becomes

$$
V\left(\alpha_{i, t}, l f_{i, t-1}\right)=\operatorname{Max}\left\{\operatorname{Max}\left(f_{e_{i, t}}\left(\alpha_{i, t}, l f_{i, t-1}\right), \chi\right)+\beta E \operatorname{Min}\left\{V\left(\alpha_{i, t+1}, l f_{i, t}^{*}\right), \lambda_{t}\right\}, \lambda_{t}-C\right\}
$$

As a result, labor force movements in response to changes in $\alpha$ are smaller in segments with higher fixed costs. When $\alpha$ decreases, agents hesitate to move out of the segment because of the high cost involved. When $\alpha$ increases, agents hesitate to move in, knowing that if they need to subsequently leave, the cost will be high. With smaller changes in the labor force, but the same movement in employment, fluctuations in unemployment are larger for high cost sectors (see proof (iv) in the Appendix). If permanent changes tend to be concentrated in high cost sectors, then the unconditional correlation (i.e. not conditioning on mobility costs) between restructuring and unemployment will be of ambiguous value relative to the unconditional correlation between other employment changes and unemployment.

There are a couple of reasons why restructuring may be concentrated in high mobility cost segments. First, restructuring may be more likely to affect workers earning rents, who may be less likely to move in response to layoffs. In the context of the model, leaving a segment forces a worker to forego these rents, and the present value of this loss is $C_{i}$. Summers, 1986, shows that workers in sectors with high unionization, such as the auto and steel industries, have wages higher than similar workers elsewhere, and that declines in employment in these industries tend to cause larger movements in unemployment. Given a trend toward greater international economic integration and hence greater competition for many industries, one would also predict that industries with high rents would be the most likely to undergo restructuring.

Second, restructuring may be more likely to affect workers with relatively large amounts of segment specific capital. Fallick, 1993, shows that unemployed workers with large amounts of specific human capital are less likely to leave their sector to find employment. In the context of the model, the present discounted value of the difference 
in earnings between the segment where workers have significant amounts of human capital and other segments is $C_{i}$. Oi, 1962, shows that firms should concentrate temporary cyclical layoffs among workers with less firm specific human capital. If permanent changes in employment force firms to make deeper cuts in their work forces or force them to hire skilled, as well as marginal employees, restructuring should affect a higher proportion of workers with large amounts of human segment specific capital. In support of this, plant births and deaths, which destroy all jobs at a plant, not just marginal jobs, represent a significant share of total permanent changes in employment in the manufacturing sector (Figura, 2002).

Permanent changes in demand may also have larger effects on unemployment if they are positively correlated across sectors between which the cost of moving is low. Suppose that some segments are more similar to each other than other segments. For example, assume that there are $s$ labor market divisions, where $M / s$ is an integer greater than 1 and less than $M$. To move across divisions, workers must pay a fixed $\operatorname{cost}, C$, but within a division there is no fixed cost for movement between labor market segments. Then changes in technology across segments will have larger effects on unemployment if these changes are positively correlated within divisions. If divisions with adverse relative technology shocks are also divisions with beneficial relative shocks, then unemployment movements within a division will be small. However, when divisions with a relatively large number of adverse shocks are also divisions where there are a relatively small number of beneficial changes, then the change in unemployment will be larger. Thus, if restructuring tends to be positively correlated among segments where mobility is relatively costless, then it can have a larger effect on unemployment than other employment changes (see proof (v) in the Appendix).

Juhn, Murphy and Topel (1991) exemplify a large body of research, which finds that unemployment has risen disproportionately among low-wage or low-skill workers and attributes the rise to an adverse shift in the demand for unskilled labor. The relative rise in unemployment for low-skill workers has been long-lasting and the adverse demand shift against low-skilled labor has been strongly positively correlated across jobs employing low skill workers. Thus, the opportunities for a low-skill worker to move to a better job when her own job has suffered an adverse demand shock have been reduced 
because jobs to which it is relatively costless (requiring little skill up-grading) to move have also suffered adverse shocks.

\section{Estimating Equation}

To estimate the effect of restructuring on unemployment I start with equation (15) which relates changes in unemployment to changes in employment and the labor force. Then I use the fact that changes in employment can be decomposed into permanent and temporary job creation and permanent and temporary job destruction

$$
\begin{aligned}
& \Delta \ln e_{s, t}=\Delta \ln \left(e p_{s, t}\right)+\Delta \ln \left(e t_{s, t}\right) \\
& \Delta \ln \left(e p_{s, t}\right) \approx p j c_{s, t}-p j d_{s, t}, \Delta \ln \left(e t_{s, t}\right) \approx t j c_{s, t}-t j d_{s, t}
\end{aligned}
$$

where $\Delta \ln (e)$ is the $\log$ difference in employment, ep is permanent employment, et is temporary employment, $p j c$ is permanent job creation and pjd is permanent job destruction.

Next, equation (19) models changes in the labor force as caused by previous changes in unemployment (the discouraged worker effect) plus the pattern of recent job flows, which accounts for the potential differences in labor force movements caused by permanent and temporary employment changes. In addition, there may be unobserved factors that cause variations in the labor force. These factors are accounted for in equation (19) if they are constant across time but vary across states or if they are common across states but vary across time.

$$
\begin{aligned}
& \Delta \ln l f_{s, t}=\alpha_{s}+\theta_{t}+\beta(L) \Delta u_{s, t-1}+\Gamma(L) J F_{s, t}+\varepsilon_{s, t} \\
& \Gamma_{i}=\left(\begin{array}{llll}
\gamma_{i}^{1} & \gamma_{i}^{2} & \gamma_{i}^{3} & \gamma_{i}^{4}
\end{array}\right) ; J F_{s, t}=\left(\begin{array}{c}
p j c_{s, t} \\
p j d_{s, t} \\
t j c_{s, t} \\
t j d_{s, t}
\end{array}\right)
\end{aligned}
$$

$\beta(L)$ and $\Gamma(L)$ represent polynomial distributed lags. Combining (15), (18) and (19) yields my estimating equation (20)

$$
\begin{aligned}
& \Delta u_{s, t}=\alpha_{s}+\theta_{t}+\beta(L) \Delta u_{s, t-1}+\Psi(L) J F_{s, t}+\varepsilon_{s, t} \\
& \Psi_{0}=\Gamma_{0}-1, \Psi_{i}=\Gamma_{i}, i \neq 0 ; \quad \varepsilon_{s, t} \sim \text { i.i.d. }
\end{aligned}
$$


In order for estimation of (20) to provide unbiased coefficients, the estimation must control for supply induced movements in employment, which may cause correlation between the right hand side variables and the error term. For example, the availability of air conditioning likely made living in the southwest region of the United State much more attractive and led to a movement in population from other states to the southwest. Labor supply induced movements such as this would be expected to lower both employment and the unemployment rate in states from which workers move and raise employment and the unemployment rate in states to which move, see Blanchard and Katz, 1992. If such movements accounted for a significant portion of the variance of permanent job flows, they would bias toward zero coefficients on permanent job creation and permanent job destruction.

However, Blanchard and Katz, 1992, did not find any support for the notion that cyclical movements in state-level employment have an important supply-induced component. In addition, equation (20) controls for supply-induced movements in employment under the assumption that most supply induced movements are low frequency - the shift in population toward the southwest following the invention of air conditioning, for example. Assuming these low frequency movements can be represented by linear trends, which may differ across states, first differencing the data and the inclusion of state dummies accounts for them.

Finally in estimating equation (20), one would also want to control for changes in the coherence of demand shocks across states. For example, an adverse labor demand shock in state $s$ at time $t$ will cause a smaller reduction in the labor force in state $\mathrm{s}$ if other states also experenced and adverse demand shock at time $t$-in equation (11) $\lambda_{t}$ would be positively correlated with $\alpha_{i, t}$. The time dummies in equation (20) control for these changes in coherence.

Equations (15) and (19) show that employment changes and job flows will have both a direct $\left(\Delta e_{t}\right)$ and an indirect effect $\left(\Gamma(L) \Delta e_{t}\right)$ on the unemployment rate. If employment declines (increases) and the labor force remains constant, then the unemployment rate must decline (increase) approximately one for one with percent changes in employment. This is the direct effect, and the movements that restructuring 
imparts to unemployment via this effect are governed by the time series properties of permanent job flows.

In addition, to the direct effect of job flows on unemployment, there is an indirect effect arising from the fact that some workers flowing into and out of employment may exit the labor force instead of entering unemployment, or some non-employed workers may react to a change in job flows by dropping out of or entering the labor force. Given a direct effect of 1 for a change in employment, the indirect effect will be $\sum_{i} \gamma_{i}^{j}-1$, $j=1,2,3,4$.

\section{Data}

\section{Sources}

The unemployment rate data are from a data set used by Blanchard and Katz (1992) and made available by the BLS. It has annual observations on unemployment in each state and the District of Columbia from 1976-2000. In addition, data on 27 states are available back to 1970. The data derive from annual averages of measures of unemployment from the Current Population Survey. Data on job flows come from the BLS' Current Employment Statistics (CES). The CES data cover a long time period, 1939-present, but its industry detail is limited to one-digit SIC. While the CES is a sample survey covering approximately 30-40 percent of employment, it is benchmarked annually to Unemployment Insurance records, and thus at annual frequencies, the data provide a near universal accounting of state-level employment.

\section{Defining Permanent and Temporary Employment movements}

Under some reasonable assumptions discussed in Figura (2003), restructuring can be measured using permanent changes in employment. To measure permanent changes, I apply a low pass filter to time series of state/industry level employment. The filter is a symmetric backward and forward weighted moving average of state/industry employment, with weights chosen to isolate particular frequencies of employment movements, see Baxter and King, 1999. I identify restructuring as long-term or persistent movements in employment. Thus, if an industry loses 1,000 jobs and this job 
loss persists for some time, I attribute the job loss to restructuring. If, instead, job losses are followed soon afterwards by job gains, I attribute these movements to cyclical demand fluctuations. I make an analogous distinction for job creation. ${ }^{8}$

In implementing the filter, one must choose a cut-off date to separate persistent low frequency movements from high frequency changes. Consistent with much of the literature, I use 8 years to separate cyclical employment changes from secular movements. ${ }^{9}$ A noticeable feature of the low pass filter is that it smooths the permanent component, such that permanent changes are assumed to be slow and drawn out. Figure 1 illustrates this by decomposing manufacturing employment in Michigan into permanent and temporary components. If the pattern of permanent changes is more abrupt than assumed by the filter, problems could arise when estimating the effects of permanent changes. I address this concern in the next section.

One can decompose permanent employment movements into permanent job creation and permanent job destruction. I construct permanent job flows at the industry level similarly to job flows constructed at the plant level by Davis, Haltiwanger and Schuh (1996). An industry has non-zero permanent job destruction at time $t$ if permanent employment in the industry has decreased from $t$ - 1 to $t$, and non-zero permanent job creation if permanent employment in the industry has increased from $t-1$ to $t$. Aggregate permanent job creation (destruction) is the sum of all industry-level permanent job creation (destruction) in state $s$ at time $t$. To transform flows into rates, I divide by the average of total state-level employment in $t-1$ and $t .^{10}$

8. Temporary state/industry-level job flows may contain permanent plant-level job flows if one set of plants destroys jobs permanently, and soon afterwards another set of plants within the same state/industry creates jobs permanently. Davis, Haltiwanger and Schuh (1996) show that for the manufacturing sector the level of industry job flows is considerably smaller than the level of plant-level job flows. However, Figura (2002) shows that the cyclical variation in plant-level permanent job flows is well captured by movements in industry-level permanent job flows. Thus, changes in aggregate restructuring using state/industry-level data should follow closely changes in aggregate restructuring measured by plant-level data.

9. See, for example, Stock and Watson (1999).

10. More specifically, the job flows used for the right hand side of equation (20) are the average of the twelve year-to-year monthly job flows. This corresponds to the change in annual unemployment being the average of the twelve year-to-year monthly changes. 
Characterizing Permanent Job Flows

Before turning to estimation results, it is instructive to consider some characteristics of permanent job flows. Figure 2 graphs time series of permanent and temporary job flows. The correlation between permanent employment movements and temporary movements, 0.33 , is positive, and from figure 2 the comovement between permanent and temporary job flows appears to be greater during recessions. There is some variation across recessions in the ratio of permanent to temporary job flows, with the recessions in the early 1980s and 1990s having relatively more permanent job destruction than the 1974-75 recession. But with just three recessions, it would be quite difficult with aggregate data to distinguish the effects on unemployment of structural versus cyclical employment changes.

Table 1. Permanent Job Flow Variation Across Regions and Decades

\begin{tabular}{lcccccccc}
\hline & \multicolumn{3}{c}{ Job Destruction Ratio } & \multicolumn{5}{c}{ Job Creation Ratio } \\
\cline { 2 - 9 } Region & $1971-$ & $1980-$ & $1990-$ & $1970-$ & $1971-$ & $1980-$ & $1990-$ & $1970-$ \\
& 1979 & 1989 & 1998 & 1998 & 1979 & 1989 & 1998 & 1998 \\
\hline Pacific $^{1}$ & 0.02 & 0.08 & 0.34 & 0.13 & 1.86 & 2.64 & 2.87 & 2.28 \\
Mountain & 0.01 & 0.18 & 0.04 & 0.09 & 2.08 & 1.73 & 4.04 & 2.29 \\
WN Central & 0.05 & 0.19 & 0.05 & 0.11 & 1.42 & 1.44 & 2.89 & 1.70 \\
WS Central & 0.00 & 0.37 & 0.08 & 0.19 & 2.98 & 1.22 & 3.59 & 2.33 \\
EN Central & 0.15 & 0.42 & 0.08 & 0.23 & 0.81 & 1.31 & 2.54 & 1.24 \\
ES Central & 0.02 & 0.22 & 0.13 & 0.11 & 1.21 & 1.64 & 2.90 & 1.64 \\
New England & 0.18 & 0.19 & 0.71 & 0.28 & 1.04 & 1.20 & 1.67 & 1.21 \\
Mid Atlantic & 0.49 & 0.70 & 0.70 & 0.61 & 0.86 & 1.94 & 2.08 & 1.47 \\
South Atlantic & 0.08 & 0.10 & 0.21 & 0.11 & 1.41 & 2.16 & 3.21 & 1.98 \\
\hline
\end{tabular}

1. Excludes Alaska and Hawaii.

Note. The job destruction ration is the average of permanent job destruction divided by the average of temporary job destruction. The job creation ratio is defined analogously.

10. (...continued)

$$
u_{\text {year }}=\frac{1}{12} \sum_{\text {month }=1}^{12} u_{\text {year, }, \text { mont }}, u_{\text {year }}-u_{\text {year }-1}=\frac{1}{12} \sum_{\text {mont } h=1}^{12}\left(u_{\text {year }, \text { mont } h}-u_{\text {year }-1, \text { month }}\right)
$$


However, table 1 breaks down the ratio of permanent to temporary job flows by region and by decade and shows that there is considerable variation in the amount of restructuring across states and across time. For example, the 1980s were particularly severe, in terms of permanent job destruction, for the East North Central region, where much of the auto and steel industries was concentrated, and for the West South Central region. In contrast, for the Pacific region, the 1980s was relatively benign, but the region was hit hard during the 1990s. Thus, conditioning on the total amount of job destruction occurring, if permanent job destruction causes greater (smaller) increases in unemployment than other kinds of job destruction, one would expect larger (smaller) increases in unemployment in the 1980s in the East North Central region than in the Pacific region. The relative unemployment experiences would then be reversed in the 1990s.

Table 2. Job Flows by Industry

\begin{tabular}{lcccc||cccc}
\hline & \multicolumn{3}{c}{ AVERAGE RATES } & \multicolumn{3}{c}{ TOTAL JOBS (1970-98) } \\
\cline { 2 - 8 } Industry & PJD & PJC & TJD & TJC & PJD & PJC & TJD & TJC \\
\hline Mining & 2.6 & 2.2 & 4.5 & 4.8 & 558 & 516 & 1097 & 1088 \\
Construction & 1.0 & 3.1 & 3.6 & 3.9 & 1226 & 3906 & 4434 & 4436 \\
Manufacturing & 0.8 & 0.7 & 1.7 & 1.9 & 4798 & 3845 & 10487 & 10034 \\
TPU & 0.2 & 1.6 & 1.2 & 1.2 & 259 & 2548 & 1884 & 1810 \\
Trade & 0.1 & 2.4 & 0.9 & 1.0 & 410 & 15125 & 6067 & 5866 \\
FIRE & 0.1 & 2.5 & 0.9 & 0.9 & 180 & 4013 & 1464 & 1563 \\
Services & 0.0 & 4.7 & 1.1 & 1.1 & 0 & 27882 & 6456 & 6409 \\
\hline
\end{tabular}

1. In thousands.

Table 2 shows the industry breakdown of permanent and temporary job flows. As one would expect, the highest rates of temporary job creation, $t j c$, and temporary job destruction, $t j d$, occur in the more cyclically sensitive goods producing industries. Unsurprisingly, the largest destroyer of permanent jobs over the 29 years from 1970 to 1998 has been the manufacturing sector, though the smaller mining and construction sectors have had larger rates of permanent job destruction on average. Permanent job 
destruction in the retail and wholesale trade industry has been negligible, while in the services industry it has been nonexistent. Services and trade have created the most permanent jobs since 1970, though all sectors, including those with large amounts of permanent job destruction, have created a significant number of permanent jobs. For example, the manufacturing sector has created nearly four million permanent jobs since 1970.

\section{Results}

\section{Direct Effect of Restructuring on Unemployment}

From equations (15) and (18) the change in unemployment caused by the direct effect of restructuring, $\Delta u^{p}$, is

$$
\Delta u_{s, t}^{p}=\Delta \ln \left(e p_{s, t}\right)
$$

Thus, one can decompose the standard deviation of the change in unemployment due to the direct effect into a restructuring term a non-restructuring term and a covariance term. Under this calculation, restructuring accounts for about one-quarter of the variation in the change in unemployment, other employment changes account for about three-fifths, with the covariance term accounting for the remainder.

However, because $u_{s, t}=u_{s, 0}+\sum_{m=1}^{t} \Delta u_{s, m}$, the variance of $u_{s, t}$ conditional on $\mathrm{u}_{\mathrm{s}, 0}$, $\operatorname{VAR}\left(u_{s, t}\right) \mid \mathrm{u}_{\mathrm{s}, 0}=\mathrm{u}$, depends on the variance and autocovariances of $\Delta u_{s, t}$.

$$
\operatorname{Var}\left(u_{s, t} \mid u_{s, 0}=\bar{u}\right)=\left\{\begin{array}{l}
\sum_{i=1}^{t} \operatorname{Var}\left(\Delta u_{s, i} \mid u_{s, 0}=\bar{u}\right)+ \\
2 \sum_{i}^{t} \sum_{j>i} \operatorname{Cov}\left(\Delta u_{s, i}, \Delta u_{s, j} \mid u_{s, 0}=\bar{u}\right)
\end{array}\right\}
$$

Lines 1 and 2 of table 3 shows that covariances of permanent employment changes are much larger than for other employment changes. Thus, the direct effect of restructuring on the variation in unemployment is greater than its influence on the change in unemployment. Unlike temporary changes in employment, permanent employment changes in an industry do not have to engender permanent changes in the opposite 
direction in the same or in different industries within a state at some point in the future. Thus, changes in employment due to industrial restructuring have the potential to be very persistent. As the last column of line 1 of table 3 shows, this is the case; the sum of autocorrelations from $t$ to $t-8$ is greater than one, not zero. As a result, net migration must occur for industrial restructuring not to have long-lasting effects on unemployment. ${ }^{11,12}$

Table 3. Dynamic Correlations of Job Flows

\begin{tabular}{|c|c|c|c|c|c|c|c|c|c|c|}
\hline & \multicolumn{10}{|c|}{$i$} \\
\hline & 8 & 7 & 6 & 5 & 4 & 3 & 2 & 1 & 0 & Sum \\
\hline$\Delta e p_{t}$ with $\Delta e p_{t-i}$ & -0.15 & -0.27 & -0.35 & -0.32 & -0.14 & 0.15 & 0.50 & 0.80 & 1 & 1.22 \\
\hline$\Delta e t_{t}$ with $\Delta e t_{t-i}$ & -0.22 & -0.16 & 0.08 & 0.14 & -0.14 & -0.41 & -0.42 & 0.16 & 1 & .03 \\
\hline$p j c_{t}$ with $p j d_{t-i}$ & 0.06 & 0.18 & 0.26 & 0.26 & 0.13 & -0.10 & -0.36 & -0.53 & -0.57 & -0.67 \\
\hline$p j d_{t}$ with $p j c_{t-i}$ & 0.16 & 0.24 & 0.28 & 0.28 & 0.17 & -0.02 & -0.25 & -0.44 & -0.57 & -0.15 \\
\hline
\end{tabular}

Note. Sum is the sum of correlations from $i=0$ to $i=8$.

Though net permanent employment changes do not bring forth net permanent employment changes in the opposite direction in the future, it could still be that permanent job creation or permanent job destruction cause increases in permanent job destruction or permanent job creation, either contemporaneously or in the near future,

11. This point is similar to that made in Blanchard and Katz, 1992. However, as Hall, 1992, pointed out in his discussion of that paper, that result followed directly from Blanchard and Katz's definition of permanent employment changes. Under the definition of industrial restructuring in this paper, permanent job changes in one industry within a state can engender permanent job changes of equal magnitude and of opposite direction in the future. Thus, permanent changes at the industry level do not necessarily lead to permanent changes in employment at the state level and the need for net migration. That they do is an empirical result.

12. Because by the construction of the low-pass filter individual industry/state permanent job flows are more persistent, the relatively larger autocovariances of permanent employment changes may seem at first uninteresting. But permanent employment changes at the state-level involve the summing of individual industries; consequently, as shown below, average state-level autocovariances depend on the correlations of permanent employment changes across industries, as well as individual industry autocovariances.

$$
E\left(\Delta e p_{t}, \Delta e p_{t-i}\right)=\sum_{j} E\left(\Delta e p_{j, t}, \Delta e p_{j, t-i}\right)+\sum_{j} \sum_{j \neq m} E\left(\Delta e p_{j, t}, \Delta e p_{m, t-i}\right)
$$

In fact, about 95 percent of the dynamic correlations of permanent employment are accounted for by dynamic covariances across rather than within industries within states. 
just not in sufficient magnitude to prevent a net change in permanent employment. Lines 3 and 4 of table 3 shows that this is not the case. Permanent job creation and permanent job destruction are, in fact, negatively correlated contemporaneously and at leads and lags of one and two years. Thus, restructuring in one industry is not mitigated by increased hiring in a different industry within a state; instead the decline in the state job market is amplified by reduced job creation in other industries.

The results for net permanent employment changes may also mask important differences between how state economies react to increases in permanent job destruction and permanent job creation. Lines 3 and 4 of table 3 show that neither permanent job destruction nor permanent job creation brings forth sufficient amounts of permanent employment changes in the opposite direction to prevent net permanent employment from changing. However, it appears that reversion in permanent employment changes is stronger for permanent job creation, implying that permanent job destruction may lead to more persistent changes in unemployment.

Table 4. Average State level Correlations between Job Flows

\begin{tabular}{lcccc}
\hline Correlation Between & $1971-1979$ & $1980-1989$ & $1990-1998$ & $1971-1998$ \\
\hline Permanent Job Creation and & -0.31 & -0.36 & -0.61 & -0.19 \\
Permanent Job Destruction & $(0.03)$ & $(0.01)$ & $(<0.01)$ & $(0.18)$ \\
\hline
\end{tabular}

Note. Significance levels (the probability that the correlation equals zero) are reported in parentheses.

Table 4 offers a different look at the relationship between permanent job creation and permanent job destruction within a state. It reports the correlation across states of average permanent job creation and average permanent job destruction. For the full sample the correlation is negative, but significant only at the twenty percent level. However, for the two most recent decades, the correlation has grown more negative and was significant at the one percent level in both the 1980s and the 1990s. The implication is that states that destroy a lot of jobs are not states that create a lot of jobs.

The above analysis suggests that permanent job destruction does not lead to permanent job creation. Therefore, unless there is greater mobility in response to restructuring-related changes in employment, restructuring will lead to more persistent movements in unemployment than other kinds of employment changes. 


\section{Total Effect of Restructuring on Unemployment}

The total effect of restructuring on unemployment can be seen in table 5, which reports results from the estimation of (20). I use two lags in the polynomials on job flows and two lags of the dependent variable. ${ }^{13}$ Observations are weighted by the level of employment in the state in the relevant year. The first column of the table shows estimates using net changes in permanent and temporary employment (the coefficients on permanent job creation and permanent job destruction are constrained to be equal in absolute value and opposite in sign), while the second column decomposes each type of employment movement into a job creation and a job destruction component.

Three features of the estimated coefficients are of particular interest. First, permanent movements in employment cause a larger initial effect on unemployment than temporary movements. Second, lagged permanent employment movements also have a bigger effect on unemployment than lagged temporary employment changes, though in the opposite direction. Lastly, permanent job destruction has a bigger and more lasting impact on unemployment than permanent job creation.

The absolute value of the coefficient on permanent employment changes in column $1,0.60$, is six times larger than the absolute value of the coefficient on temporary changes. If structural changes affected the same types of workers as other employment changes, one would expect the coefficient on permanent changes in employment to be smaller in absolute value than the coefficient on temporary changes. Thus, structural shocks must have affected workers who were more immobile than other workers. The reason for their immobility is not apparent, but from the discussion above, plausible explanations are that structural changes have involved an adverse broad-based shift in the demand for low-skill workers and/or have disproportionately caused the destruction of jobs with substantial rents or with large amounts of job specific human capital.

13. Lagged dependent variables produce biased coefficient estimates when the time dimension is limited. However, because of the relatively large time dimension and the a priori expected negative coefficients on lagged unemployment, the bias imparted is likely trivial, Hsiao (1989). 
Table 5. Estimation Results

\begin{tabular}{|c|c|c|c|}
\hline & \multicolumn{2}{|c|}{ Annual } & \multirow{2}{*}{$\frac{\text { Triennial }}{(3)}$} \\
\hline & (1) & $(2)$ & \\
\hline$\Delta \mathrm{u}(-1)$ & $\begin{array}{l}-0.14 \\
(0.03)\end{array}$ & $\begin{array}{l}-0.25 \\
(0.03)\end{array}$ & $\begin{array}{c}-0.23 \\
(0.04)\end{array}$ \\
\hline$\Delta \mathrm{u}(-2)$ & $\begin{array}{l}-0.09 \\
(0.03)\end{array}$ & $\begin{array}{l}-0.24 \\
(0.03)\end{array}$ & \\
\hline PJC & $\begin{array}{l}-0.60 \\
(0.07)\end{array}$ & $\begin{array}{l}-0.40 \\
(0.06)\end{array}$ & $\begin{array}{l}-0.18 \\
(0.02)\end{array}$ \\
\hline PJD & $\begin{array}{c}0.60 \\
(0.07)\end{array}$ & $\begin{array}{c}0.67 \\
(0.13)\end{array}$ & $\begin{array}{c}0.61 \\
(0.05)\end{array}$ \\
\hline TJC & $\begin{array}{l}-0.10 \\
(0.01)\end{array}$ & $\begin{array}{c}0.05 \\
(0.01)\end{array}$ & $\begin{array}{c}0.01 \\
(0.03)\end{array}$ \\
\hline TJD & $\begin{array}{c}0.10 \\
(0.01)\end{array}$ & $\begin{array}{c}0.34 \\
(0.02)\end{array}$ & $\begin{array}{c}0.15 \\
(0.03)\end{array}$ \\
\hline PJC(-1) & $\begin{array}{c}0.51 \\
(0.13)\end{array}$ & $\begin{array}{c}0.16 \\
(0.09)\end{array}$ & $\begin{array}{c}0.09 \\
(0.02)\end{array}$ \\
\hline PJD(-1) & $\begin{array}{l}-0.51 \\
(0.13)\end{array}$ & $\begin{array}{c}0.28 \\
(0.22)\end{array}$ & $\begin{array}{l}-0.16 \\
(0.05)\end{array}$ \\
\hline $\mathrm{TJC}(-1)$ & $\begin{array}{l}-0.03 \\
(0.01)\end{array}$ & $\begin{array}{l}-0.04 \\
(0.01)\end{array}$ & $\begin{array}{l}-0.05 \\
(0.03)\end{array}$ \\
\hline TJD(-1) & $\begin{array}{c}0.03 \\
(0.01)\end{array}$ & $\begin{array}{l}-0.12 \\
(0.03)\end{array}$ & $\begin{array}{l}-0.01 \\
(0.03)\end{array}$ \\
\hline PJC(-2) & $\begin{array}{l}-0.08 \\
(0.07)\end{array}$ & $\begin{array}{c}0.09 \\
(0.05)\end{array}$ & \\
\hline PJD(-2) & $\begin{array}{c}0.08 \\
(0.07)\end{array}$ & $\begin{array}{l}-0.47 \\
(0.13)\end{array}$ & \\
\hline TJC(-2) & $\begin{array}{l}-0.01 \\
(0.01)\end{array}$ & $\begin{array}{l}-0.01 \\
(0.01)\end{array}$ & \\
\hline $\mathrm{TJD}(-2)$ & $\begin{array}{c}0.01 \\
(0.01)\end{array}$ & $\begin{array}{l}-0.06 \\
(0.02)\end{array}$ & \\
\hline $\mathrm{R}^{2}$ & 0.76 & 0.81 & 0.90 \\
\hline
\end{tabular}

Note. Column (1) imposes the constraints that the coefficients on job creation are equal the negative of the coefficients on job destruction. All regressions include state fixed effects and year dummies. Standard errors are in parentheses.

The coefficients on lagged permanent employment changes are significantly different from zero and are opposite in sign to contemporaneous coefficients of permanent employment changes. According to the model, this can occur if workers do 
not initially realize that structural changes are permanent; but as they realize the true duration of the shock (after a year), they react accordingly.

The second column of table 5 shows coefficients on the two components of restructuring, permanent job creation and permanent job destruction. The hypotheses that coefficients for permanent job creation and job destruction are equal, as well as that coefficients on temporary job creation and job destruction are equal, can be rejected at the one percent level of significance. Permanent job destruction has a larger initial impact than permanent job creation on unemployment. Moreover, even after two years the net effect of permanent job destruction, as computed by the sum of the contemporaneous and lagged coefficients, is significantly different from zero and significantly larger than the effect of permanent job creation. Apparently permanent job destruction has disproportionately affected immobile workers, and even after two years, migration or withdrawals from the labor force have not eliminated the effects of permanent job destruction on unemployment. This is not surprising, given that the explanations offered above for why permanent changes in employment might affect unemployment more than temporary changes appear more relevant for permanent job destruction than for permanent job creation.

\section{Robustness}

(i) Parameterizing labor supply induced employment movements

As discussed in section 2, identification of parameters requires that employment movements related to changes in labor supply be controlled for. Section 2 discussed the conditions under which estimation of equation (20) is unbiased: low frequency labor supply movements can be represented by a constant trend within each state. Another plausible representation is a slowly evolving trend within each state. To test this hypothesis, I include a time trend interacted with state dummies, which allows employment caused by labor supply movements to vary quadratically within each state across time. Estimation results are qualitatively similar to those in table 5, and an F test of the joint hypothesis that all year/state interactions are zero cannot be rejected at a very high level of confidence. 


\section{(ii) Spurious autocorrelation in permanent employment movements}

The conclusion that workers realize the permanence of a shock only after some time may be erroneous if it is produced by the smoothing of permanent employment movements by the low pass filter, and bias in one coefficient can affect all other coefficients in the regression. The low pass filter will spread out a sharp permanent decrease in employment in period t over periods $t-3, t-2, t-1, t, t+1, t+2, t+3$, though the bulk of the permanent movement will be concentrated in $t$. By moving back some of the change in period $t$ into periods $t-3, t-2$, and $t-1$, the low pass filter may introduce a spurious autocorrelation in permanent employment changes. Because the autocorrelation in permanent job flows decreases as the frequency of the data is reduced, using a lower frequency in the estimation of (20) should lessen this problem if it exists.

To capture the lower frequency movements in the data, I average variables over three years. Three years is a period long enough to address the above concerns about autocorrelation, but short enough to still have significant cyclical movements in the data and preserve a fair number of degrees of freedom for the estimation of (20). ${ }^{14}$ I still include one lag of the right hand side variables. Despite the potential difference between low and high frequency data, the results in column (3) are quite similar to those in column (2). The initial response to permanent job destruction is significantly larger than temporary job destruction and permanent job creation, and the coefficient on lagged permanent job destruction is significantly positive and greater than that of temporary job destruction. The relative influences of permanent and temporary job creation are also similar, with permanent job creation having a larger effect than temporary job creation.

To summarize the results in this section, both directly, because permanent job destruction does not engender permanent job creation, and indirectly, because restructuring appears to disproportionately affect low mobility workers, the effect of restructuring on unemployment is significant. To quantify this significance and see how it has changed over time, I use estimates from equation (20) to investigate how the

14. The table reports results using the following three year periods: 1971-1973, 1974-1976, ..., 1998-2000. This breakdown preserves the most variation in changes in the unemployment rate.

Other three year groupings yield similar results. 
cyclical behavior of unemployment would change if restructuring were not correlated with they cycle.

\section{Structural Changes and Aggregate Unemployment}

Though I ultimately consider the results of the counterfactual exercise at the national level, much of the media attention about restructuring and unemployment has focused on specific states, and I first look at two states, Michigan and California, that have garnered a lot of this attention. Figure 3 shows actual, predicted and counterfactual unemployment rates for the two states. To compute predicted and counterfactual unemployment rates, I use dynamic simulations of equation (20), jumping off of the three cyclical peaks in my data set: 1973, 1979, 1989. The counterfactual dynamic simulation sets the values of permanent job destruction and permanent job creation equal to their respective means over the period of each dynamic simulation.

First consider Michigan. During the early 1980s, Michigan experienced a large increase in permanent job destruction and a rise in its unemployment rate to over 15 percent. The level of permanent job destruction is lower in the recessions of 1974-5 and 1990-91, and the rise in unemployment is less severe. As shown in the top panel of figure 3, the unconstrained model captures the behavior of unemployment reasonable well. When the model is constrained to have restructuring constant over the cycle, movements in predicted unemployment have significantly less amplitude than actual unemployment, especially during the early 1980s. As the bottom panel of figure 3 shows, fluctuations in California's counterfactual unemployment rate were also damped relative to the predicted unemployment rate, most noticeably in the 1990 s, when there were large increases in permanent job destruction.

Figure 4 shows predicted and counterfactual unemployment at the national level. These are computed by summing the state-level variables, weighted by state employment. ${ }^{15}$ The relative importance of restructuring appears to have increased over time, so that by the 1990-91 recession and subsequent recovery, it accounted for a

15. The correct procedure would be to weight by labor force, but reliable labor force data are not available and weighting by employment is a good approximation. 
considerable portion of the movement in unemployment. Table 6 bears out this conclusion by comparing standard deviations of the dynamic simulations of predicted and counterfactual unemployment. As was suggested by figure 4, the influence of structural changes has increased steadily over time, accounting for very little of the variation in unemployment in the 1970 s, about 15 percent in the 1980 s and close to 50 percent in the 1990s.

\section{Table 6. Standard Deviation of Unemployment}

\begin{tabular}{lccc}
\hline & $1973-1979$ & $1979-1989$ & $1989-1998$ \\
\cline { 2 - 4 } Observed Unemployment & 1.32 & 1.50 & 0.96 \\
Counterfactual Unemployment & 1.28 & 1.26 & 0.51 \\
\hline
\end{tabular}

Note. Counterfactual Unemployment assumes a constant rate of permanent job creation and permanent job destruction.

\section{Conclusion}

This paper suggests that over a period of time when other forces were acting to reduce macroeconomic volatility, industrial restructuring acted to significantly increase the variance of unemployment. The likely reasons are, first, that restructuring has become more cyclically concentrated, with permanent job destruction accounting for a larger share of the increase in job destruction in recessions. Second, restructuring has predominantly affected workers with high attachment to their particular state/industry labor markets, and third, workers are not at first certain that restructuring-related employment changes are permanent. 


\section{Appendix}

(i) Restructuring is concentrated in downturns

For a segment on the downward adjustment margin,

$$
\operatorname{Max}\left(\chi, f_{e}\left(\alpha_{i, t}, l f_{i, t}^{*}\right)\right)+E \beta V\left(\alpha_{i, t+1}, l f_{i, t}^{*}\right)=E \lambda_{t}
$$

Using the implicit function theorem, one gets

$$
\frac{\partial f_{i, t}^{*}}{\partial \bar{\alpha}}=\frac{\frac{\partial f_{e}\left(\alpha_{i, t}, l f_{i, t}^{*}\right)}{\partial \bar{\alpha}}+E \beta \frac{\partial V\left(\alpha_{i, t+1}, l f_{i, t}^{*}\right)}{\partial \bar{\alpha}}-\frac{\partial \lambda_{t}}{\partial \bar{\alpha}}}{-\left(\frac{\partial f_{e_{i, t}}\left(\alpha_{i, t}, l f_{i, t}^{*}\right)}{\partial f_{i, t}^{*}}+E \beta \frac{\partial V\left(\alpha_{i, t+1}, l f_{i, t}^{*}\right)}{\partial f_{i, t}^{*}}-\frac{\partial \lambda_{t}}{\partial f_{i, t}^{*}}\right)}
$$

If $\frac{\partial V\left(\alpha_{i, t}, f_{i, t}^{*}\right)}{\partial \alpha_{i, t}}$ and $\frac{\partial V\left(\alpha_{i, t}, l f_{i, t}^{*}\right)}{\partial f_{i, t}}$ are non-increasing in $V$, then using equation (8), the expression in (A2) is positive, implying that in a marginal sector the labor force declines when $\alpha$ declines.

When there exists unemployment in the marginal sector, the first terms in the numerator and denominator become 0 , and the effect is attenuated and depends on $\frac{\partial V\left(\alpha_{i, t}, l f_{i, t}^{*}\right)}{\partial \alpha_{i, t}}$ and $\frac{\partial V\left(\alpha_{i, t}, l f_{i, t}^{*}\right)}{\partial f_{i, t}}$ being decreasing in $V$.

(ii) Permanent changes in employment cause smaller movements in unemployment From equation (7) only the current level of $\alpha$ affects the level of employment in segment $i$. Therefore, employment changes due to permanent (long duration) and temporary (short duration) changes in $\alpha$ will be the same. From equation (15), this implies that only a difference in the labor force movements will cause permanent changes to have a different effect on unemployment than temporary changes.

The proof is simple when short duration changes are white noise. Then for short duration changes $\frac{\partial V\left(\alpha_{i, t+1}, l f_{i, t-1}\right)}{\partial \alpha_{i, t}}=0$, and for long duration changes 
$\frac{\partial V\left(\alpha_{i, t+1}, l f_{i, t-1}\right)}{\partial \alpha_{i, t}}>0$. Using the implicit function theorem and equations (A1) and (A3) below, $\frac{\partial f_{i, t}^{*}}{\partial \alpha_{i, t}}$ is larger for long duration than for short duration changes.

For the more general case of short duration and long duration changes, first, consider a change in $\alpha$ causing the labor force to increase. Then

$$
V\left(\alpha_{i, t}, l f_{i, t-1}\right)=f_{e_{i, t}}\left(\alpha_{i, t}, l f_{i, t-1}\right)+E \lambda_{t}
$$

Given the nature of the shocks to $\alpha$ and the fact that segment $i$ is attracting labor force inflows, the entire labor force must be employed in period $t$. In addition, the expected labor force inflows will drive the expected value of being in segment $i$ next period to equal $\lambda_{t}$.

To see which change (permanent or temporary) causes a greater change in the labor force, one needs to measure

$$
E\left(V\left(\alpha_{i, t+1}^{p}, l f_{i, t-1}\right)-V\left(\alpha_{i, t+1}^{p}, l f_{i, t}^{*}\right)\right)-E\left(V\left(\alpha_{i, t+1}^{t}, l f_{i, t-1}\right)-V\left(\alpha_{i, t+1}^{t}, l f_{i, t}^{*}\right)\right)
$$

where $\alpha_{i, t}^{p}$ means that the change in $\alpha$ is permanent and $\alpha_{i, t}^{t}$ means that the change is temporary. If this difference is greater than zero, then the labor force response to a permanent change must be greater. This follows from

$$
\beta V\left(\alpha_{i, t+1}^{p}, l f_{i, t}^{*}\right)=\beta V\left(\alpha_{i, t+1}^{t}, l f_{i, t}^{*}\right)=\lambda_{t}, \Delta l f_{i, t}=l f_{i, t}-l f_{i, t-1}=l f_{i, t}^{*}-l f_{i, t-1}
$$

and

$$
\frac{\partial V\left(\alpha_{i, t}, l f_{i, t-1}\right)}{\partial f_{i, t-1}}<0
$$

where the inequality in (A6) comes from applying the envelope theorem to equation (12).

From (12)

$$
E \beta V\left(\alpha_{i, t+1}, l f_{i, t-1}\right)=E f_{e}\left(\alpha_{i, t+1}, l f_{i, t-1}\right)+E \beta \operatorname{Max}\left(V\left(\alpha_{i, t+2}, l f_{i, t+1}^{*}\right), \lambda_{t+1}\right)
$$


Also, the following equality will be useful later on. It applies when labor force inflows force the expected value of being in a segment the following period to equal $\lambda_{t}$ and when $\alpha_{i, t}=\alpha_{i, t+1}$.

$$
V^{t}\left(\alpha_{i, t}, l f_{i, t-1}\right)=f_{e}\left(\alpha_{i, t}, l f_{i, t-1}\right)+E \lambda_{t}=V^{t+1}\left(\alpha_{i, t+1}, l f_{i, t-1}\right)+E \lambda_{t+1}-E \lambda_{t}
$$

If the duration of $\Delta \alpha^{t}$ is one period, then $\alpha_{i, t+2}^{t}=\bar{\alpha}<\alpha_{i, t+2}^{p}$.

By the envelope theorem

$$
\frac{\partial V\left(\alpha_{i, t}, l f_{i, t-1}\right)}{\partial \alpha_{i, t}}=\left\{\begin{array}{ll}
\left(\frac{\partial f_{e}\left(\bar{\alpha}, l f_{i, t-1}\right)}{\partial \alpha_{i, t}}+E \beta \frac{\partial V\left(\alpha_{i, t+1}, l f_{i, t-1}\right)}{\partial \alpha_{i, t}}\right) & \alpha_{i, t} \in R(0) \\
\sum_{k=1}^{K} \frac{\partial \lambda_{t}}{\partial f_{k, t}^{*}} \frac{\partial f_{k, t}^{*}}{\partial f_{i, t}^{*}} \frac{\partial f_{i, t}^{*}}{\partial \alpha_{i, t}} & \alpha_{i, t} \in R(+) \\
\sum_{k=1}^{K} \frac{\partial \lambda_{t}}{\partial f_{k, t}^{*}} \frac{\partial f_{k, t}^{*}}{\partial f_{i, t}^{*}} \frac{\partial f_{i, t}^{*}}{\partial \alpha_{i, t}} & \alpha_{i, t} \in R(-)
\end{array}\right\}
$$

where $\mathrm{R}(0)$ is the region where there is no change in the labor force, $\mathrm{R}(+)$ is the region where there is an increase in the labor force, and $\mathrm{R}(-)$ is the region where there is a decrease in the labor force. In all three regions, the derivative is positive.

Therefore, if $\lambda_{t+1} \geq \beta V\left(\alpha_{i, t+2}^{p}, l f_{i, t+1}^{* p}\right)>\beta V\left(\bar{\alpha}, l f_{i, t+1}^{*}\right), \quad$ then from (A7)

$$
V\left(\alpha_{i, t+1}^{p}, l f_{i, t-1}\right)>V\left(\alpha_{i, t+1}^{t}, l f_{i, t-1}\right)
$$

and (A4) is positive.

$$
\begin{aligned}
& \text { If } \beta V\left(\alpha_{i, t+2}^{p}, l f_{i, t+1}^{* p}\right)=\beta V\left(\bar{\alpha}, l f_{i, t+1}^{* t}\right)=\lambda_{t} \text {, then } l f_{i, t+1}^{* p}>l f_{i, t+1}^{* t} . \text { This implies that } \\
& V\left(\alpha_{i, t+2}^{p}, l f_{i, t-1}\right)>V\left(\alpha_{i, t+2}^{t}, l f_{i, t-1}\right), \text { which given (A8) implies (A10) so that (A4) is }
\end{aligned}
$$
positive.

If the duration of the short-term change is longer than one period, one can repeat the same steps. First, updating (A7)

$$
V\left(\alpha_{i, t+n_{2}}, l f_{i, t-1}\right)=f_{e}\left(\alpha_{i, t+n_{2}}, l f_{i, t-1}\right)+\operatorname{EMin}\left(\beta V\left(\alpha_{i, t+n_{2}+1}, l f_{i, t+n_{2}}^{*}\right), \lambda_{t+n_{2}}\right)
$$


Then finding that because $\quad \alpha_{i, t+n_{2}+1}^{t}=\bar{\alpha}<\alpha_{i, t+n_{2}+1}^{p} \quad$, either

$V\left(\alpha_{i, t+n_{2}+1}, l f_{i, t+n_{2}}^{*}\right)>V\left(\bar{\alpha}, l f_{i, t+n_{2}}^{*}\right) \quad$ or $l f_{i, t+n_{2}}^{* p}>l f_{i, t+n_{2}}^{*}$. If the former, then given (A11) $V\left(\alpha_{i, t+n_{2}}^{p}, l f_{i, t-1}\right)>V\left(\alpha_{i, t+n_{2}}^{t}, l f_{i, t-1}\right)$, which using (A8) and working backwards, implies (A10) and (A4) is positive. In the latter case, from (A2) this implies $V\left(\alpha_{i, t+n_{2}}^{p}, l f_{i, t-1}\right)>V\left(\alpha_{i, t+n_{2}}^{t}, l f_{i, t-1}\right)$, and the same result applies.

For decreases in the labor force,

$$
\lambda_{t}=\operatorname{Max}\left(\chi, f_{e}\left(\alpha_{i, t}, l f_{i, t}^{*}\right)\right)+E \beta V\left(\alpha_{i, t+1}, l f_{i, t}^{*}\right)
$$

and one can repeat the same steps as for increases in the labor force, showing that at $n_{2}$ either $V\left(\alpha_{i, t+n_{2}+1}^{p}, l f_{i, t+n_{2}}^{*}\right)<V\left(\bar{\alpha}, l f_{i, t+n_{2}}^{*}\right)$ or that $l f_{i, t+n_{2}-1}^{* p}<l f_{i, t+n_{2}}^{*_{t}}$.

(iii) Uncertainty produces smaller initial reactions to permanent changes

Define $V^{i, n_{i}, t+1}\left(\alpha_{i, t}, l f_{i, t-1}\right)$ to be the value of being in segment $i$ if the change to $\alpha_{i}$ in the

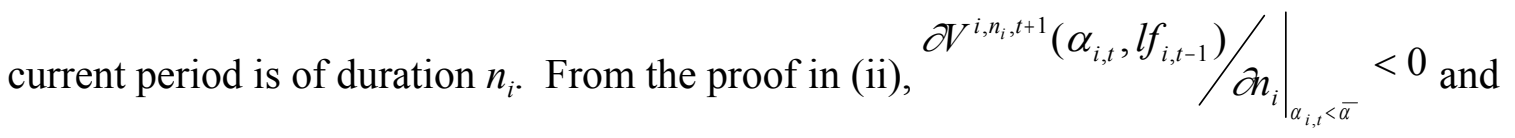
$\partial V^{i, n_{i}, t+1}\left(\alpha_{i, t}, l f_{i, t-1}\right) /\left.\partial n_{i}\right|_{\alpha_{i, t}>\bar{\alpha}}>0$. The probability that the change in $\alpha$ is long duration

given that it has lasted $g$ periods, $P_{l, g}=\operatorname{Pr}(\Delta \alpha=l \mid d=g)$, is given by equation (16); the probability that the change is short duration given that it has lasted $g$ periods is $1-P_{l, g}$. This implies

$$
\beta E V^{i, t+1}\left(\alpha_{i, t+1}, l f_{i, t-1}\right)=\beta\left\{P_{l, g} V^{i, n_{1}, t+1}\left(\alpha_{i, t+1}, l f_{i, t-1}\right)+\left(1-P_{l, g}\right) V^{i, n_{2}, t+1}\left(\alpha_{i, t+1}, l f_{i, t-1}\right)\right\}
$$

which is less than $V^{i, n_{1}, t+1}$ if $\alpha_{i, t}>\bar{\alpha}$ and greater than $V^{i, n_{1}, t+1}$ if $\alpha_{i, t}<\bar{\alpha}$. Therefore, from the proof in (ii) above, the absolute value of labor force movements should be smaller in response to permanent changes in $\alpha$ when there is uncertainty. 
Initially, if $P_{l, g}=\pi_{x}$, then the response to a permanent and temporary shock will be the same. Then if $\frac{\partial P_{l, g}}{\partial g}>0$, the labor force movement should increase over time, with the level of $l f_{i}$ reaching the level in the certainty case when $P_{l, g}=1$.

(iv) Fixed costs inhibit mobility

The labor force response to a change in $\alpha$ depends on the region of labor force responses, $(0,+,-)$ that $\alpha$ is in. $C$ has an effect on labor force responses by increasing the size of the region of no response, region (0). Even when $\alpha$ reaches an extreme enough value to cause a change in the labor force, the level of the labor force will be larger for a given $\alpha$ when the labor force declines and smaller when the labor force increases than in a sector with smaller costs.

Define $\alpha^{*}$ as

$$
\operatorname{Max}\left\{f_{e}\left(\alpha_{i, t}^{*}, l f_{i, t}^{*}\right), \chi\right\}+\beta E V\left(\alpha_{i, t+1}, l f_{i, t}^{*} ; C\right)=\lambda_{t}-C
$$

and $\alpha^{* *}$ as

$$
V\left(\alpha_{i, t}^{* *}, l f_{i, t-1} ; C\right)=\operatorname{Max}\left\{f_{e}\left(\alpha_{i, t}^{* *}, l f_{i, t-1}\right), \chi\right\}+\beta E \lambda_{t}
$$

$\alpha^{*}$ and $\alpha^{* *}$ are threshold values, where labor force responses switch from no movement to decreasing and increasing respectively.

With fixed costs, the value of being in segment $i$ is

$$
\begin{aligned}
& V\left(\alpha_{i, t}, l f_{i, t-1} ; C\right)=\operatorname{Max}\left\{\begin{array}{l}
\operatorname{Max}\left(f_{e}\left(\alpha_{i, t}, l f_{i, t-1}\right), \chi\right)+ \\
E \beta \operatorname{Min}\left(V\left(\alpha_{i, t+1}\left(\alpha_{i, t}\right), l f_{i, t-1} ; C\right), \lambda_{t}\right), \lambda_{t}-C
\end{array}\right\}= \\
& \left.\operatorname{Pr}\left(\alpha^{*}<\alpha_{i, t}<\alpha^{* *}\right)\left(f_{e}\left(\alpha_{i, t}, l f_{i, t-1}\right), \chi\right)+E \beta V\left(\alpha_{i, t+1}\left(\alpha_{i, t}\right), l f_{i, t-1} ; C\right)\right)+ \\
& \operatorname{Pr}\left(\alpha^{*}>\alpha_{i, t}\right)\left(\lambda_{t}-C\right)+\operatorname{Pr}\left(\alpha^{* *}<\alpha_{i, t}\right)\left(\operatorname{Max}\left(f_{e}\left(\alpha_{i, t}, l f_{i, t-1}\right), \chi\right)+\lambda_{t}\right)
\end{aligned}
$$

Then 


$$
\frac{\partial V\left(\alpha_{i, t}, l f_{i, t-1} ; C\right)}{\partial C}=\left\{\begin{array}{l}
\Phi_{t}\left(\alpha^{*}\right)\left(\frac{\partial \lambda}{\partial C}-1\right)+\left(1-\Phi_{t}\left(\alpha^{* *}\right)\right) \frac{\partial \lambda}{\partial C}+ \\
\varphi\left(\alpha^{*}\right) \frac{\partial \alpha^{*}}{\partial C}\left(\begin{array}{l}
\lambda_{t}-C-f_{e}\left(\alpha_{i, t}, l f_{i, t-1}\right)- \\
E \beta V\left(\alpha_{i, t}, l f_{i, t-1} ; C\right)
\end{array}\right)+ \\
\varphi\left(\alpha^{* *}\right) \frac{\partial \alpha^{* *}}{\partial C}\left(\lambda_{t}-E \beta V\left(\alpha_{i, t}, l f_{i, t-1} ; C\right)\right)
\end{array}\right\}
$$

Differentiating equations (A13) and (A14), and using (A16), one gets three equations in three unknowns: $\frac{\partial \alpha^{*}}{\partial C}, \frac{\partial \alpha^{* *}}{\partial C}$, and $\frac{\partial V}{\partial C}$. Some tedious algebra shows that $\frac{\partial \alpha^{*}}{\partial C}<0$, $\frac{\partial \alpha^{* *}}{\partial C}>0$, that $-1<\frac{\partial V}{\partial C}<0$ which implies that the region of no action expands as $C$ increases.

Also, from (A13) and (A14) and because $-1<\frac{\partial V}{\partial C}<0$, the level of the labor force for a given $\alpha_{i}$ should be smaller when the labor force increased the previous period and larger when it decreased. As a result, for any discrete change in $\alpha_{i}$, which switches the segment from being on the labor force gaining margin to being on the labor force losing margin, or visa versa, the segment will have a smaller variation in its labor force than a segment with smaller fixed costs.

\section{(v) Positively correlated shocks cause larger movements in unemployment}

To make a proof tractable, suppose that mobility costs are large enough to prevent moving out of a division, but are negligible within a division, that there are two segments in each division, that $\alpha$ is independently and identically distributed white noise, and that technology takes the form

$$
f\left(\alpha_{i, t}, e_{i, t}\right)=\alpha_{i, t} e_{i, t}-b e_{i, t}^{2}
$$

Then unemployment in each segment is

$$
u_{i, t}=l f_{i, t}-e_{i, t}=l f_{i, t}-\left(\frac{\alpha_{i, t}-\chi}{b}\right) ; i=1,2
$$


where negative unemployment is interpreted as causing a decrease in unemployment in the other segment within a division. Therefore, total unemployment in the division is

$$
U_{t}=u_{1, t}+u_{2, t}=l f_{1, t}+l f_{2, t}-\left(\frac{\alpha_{1, t}-\chi}{b}\right)-\left(\frac{\alpha_{2, t}-\chi}{b}\right)
$$

The variance of $U_{t}$ conditional on beginning period labor forces is

$$
\operatorname{Var}\left(U_{t} \mid l f_{1, t}, l f_{2, t}\right)=\frac{1}{b^{2}} \operatorname{Var}\left(\alpha_{1, t}\right)+\frac{1}{b^{2}} \operatorname{Var}\left(\alpha_{2, t}\right)+\frac{2}{b^{2}} \operatorname{Cov}\left(\alpha_{1, t}, \alpha_{2, t}\right)
$$

from which it follows that the variance of the unemployment rate will be greater, the greater the covariance between shocks to technology in segments 1 and 2 . 


\section{References}

Ahmed, Shaghil, Andrew Levin, and Beth Anne Wilson, "Recent U.S. Macroeconomic Stability: Good Policy, Good Practices, or Good Luck," mimeo, Federal Reserve Board (2002).

Anderson T. W. and C. Hsiao, "Formulation and Estimation of Dynamic Models Using Panel Data," Journal Of Econometrics, 60, no. 1 (1982): 47-82.

Arellano, Manuel and Stephen Bond, "Some Tests of Specification of Panel Data: Monte Carlo Evidence and an Application to Employment Equations," Review of Economic Studies, 58, no. 2 (1991): 277-97.

Bahk, Bhong-Hyong and Michael Gort, "Decomposing Learning by Doing in New Plants," Journal of Political Economy, 101, no. 4 (1993): 561-583.

Bartik, Timothy, Who Benefits from State and Local Economic Development Policies?, Kalamazoo, Michigan: W.E. Upjohn Institute for Employment Research, 1991.

Baxter, Marianne and Robert G. King, "Measuring Business Cycles: Approximate BandPass filters for Economic Time Series," The Review of Economics and Statistics 81, no. 4 (1999): 575-93.

Blanchard, Olivier Jean and Lawrence F. Katz, "Regional Evolutions," Brookings Papers on Macroeconomic Activity, 1 (1992).

Bound, John and Harry Holzer, "Demand Shifts, Population Adjustments, and Labor Market Outcomes during the 1980s," Journal of Labor Economics, 18, no. 1 (2000): 20-54.

Brainard Lael, and David Cutler (1993) "Sectoral Shifts and Cyclical Unemployment Reconsidered," The Quarterly Journal of Economics, February (1993), 219-243.

Caplin, and John Leahy, Sectoral Shocks, Learning, and Aggregate Fluctuations, Review of Economic Studies, 60, no. 4 (1993): 777-794.

Davis, Steven, John Haltiwanger, and Scott Schuh. Job Creation and Destruction, Cambridge, MA: MIT Press, 1996.

Fallick, Bruce, “The Industrial Mobility of Displaced Workers," Journal of Labor Economics, 11, no. 2 (1993): 302-323.

Figura, Andrew, "Is Reallocation Related to the Cycle? A Look at Permanent and Temporary Job Flows,” FEDS Working Paper 2002-16, Federal Reserve Board. 
Figura, Andrew, “The Creation and Destruction of Job Capital," mimeo, Federal Reserve Board (2003).

Groshen, Erica and Simon Potter, "Has Structural Change Contributed to a Jobless Recovery?” Federal Reserve Bank of New York Current Issues in Economics and Finance, 9, no. 8 (2003): 1-7.

Gabriel, Stuart, Janice Shack-Marquez and William Wascher, "Does Migration Arbitrate Regional Labor Market Differentials?” Regional Science and Urban Economics, 23 (1992): 211-233.

Hall, Robert E. "Turnover in the Labor Force," Brookings Papers on Economic Activity, no. 3 (1972), 621-33.

Hamilton, James D., “A Neoclassical Model of Unemployment and the Business Cycle," Journal of Political Economy, 96, no. 3 (1986): 593-617.

Holzer, Harry J., "Employment, Unemployment and Demand Shifts in Local Labor Markets," The Review of Economics and Statistics, 73, no. 1 (1991): 25-32.

Hsiao, Cheng, The Analysis of Panel Data, New York: Cambridge University Press (1986).

Juhn, Chinhui, Kevin Murphy and Robert Topel, "Why has the Natural Rate of Unemployment Increased Over Time?” Brookings Papers on Economic Activity, 2 (1991): 75-141.

Lilien, David, "Sectoral Shifts and Cyclical Unemployment," Journal of Political Economy 90, no. 4 (1982): 777-93.

Longani, Prakash and Trehan Bharat, "Explaining Unemployment: Sectoral vs. Aggregate Shocks," Federal Reserve Bank of San Francisco Economic Review, 1, (1997): 3-15.

Loungani, Prakesh and Richard Rogerson, "Cyclical Fluctuations and the Sectoral Reallocation of Labor: Evidence from the PSID," Journal of Monetary Economics 23, no. 2 (1989): 259-273.

Lucas, Robert E., Jr. and Edward C. Prescott, "Equilibrium Search and Unemployment," Journal of Economic Theory, 7, no. 2 (1974): 188-209.

Marston, Stephen "Two Views of the Geographic Distribution of Unemployment," Quarterly Journal of Economics, February (1985): 57-79. 
McConnell, Margaret M. and Gabriel Perez-Quiros, "Output Fluctuations in the United States: What has Changed Since the Early 1980s?" American Economic Review, Dec. (2002).

Oi, Walter, "Labor as a Quasi-fixed Factor," Journal of Political Economy, 70, no.6 (1962): 538-555.

Prescott, Edward C. And Michael Visscher (1980) “Organization Capital,” Journal of Political Economy, 88(3), pp. 446-461.

Ramey, Valerie A. and Matthew D. Shapiro (1998) "Displaced Capital: A Study of Aerospace Plant Closings," Journal of Political Economy, 109, no. 5 (2001): 95892.

Stock, James and Mark Watson, "Has the Business Cycle Changed and Why?" mimeo, Harvard University, April 2002.

Stock, James and Mark Watson, "Business Cycle Fluctuations in Macroeconomic Time Series," Handbook of Macroeconomics, Vol. 1A, John Taylor and Michael Woodford, eds. New York and Oxford: Elsevier Science, North Holland (1999).

Summers, Lawrence, "Why is the Unemployment Rate So Very High near Full Employment?", Brookings Papers on Macroeconomic Activity (1986), 339-396.

Topel, Robert, “Local Labor Markets," Journal of Political Economy, 94, no. 3, pt. 2 (1986): 111-143.

Topel, Robert, "Specific Capital and Unemployment: Measuring the Costs and Consequences of Job Loss," mimeo, University of Chicago (1990). 
Figure 1. Permanent Employment as Measured by a Low Pass Filter

Manufacturing Employment in Michigan

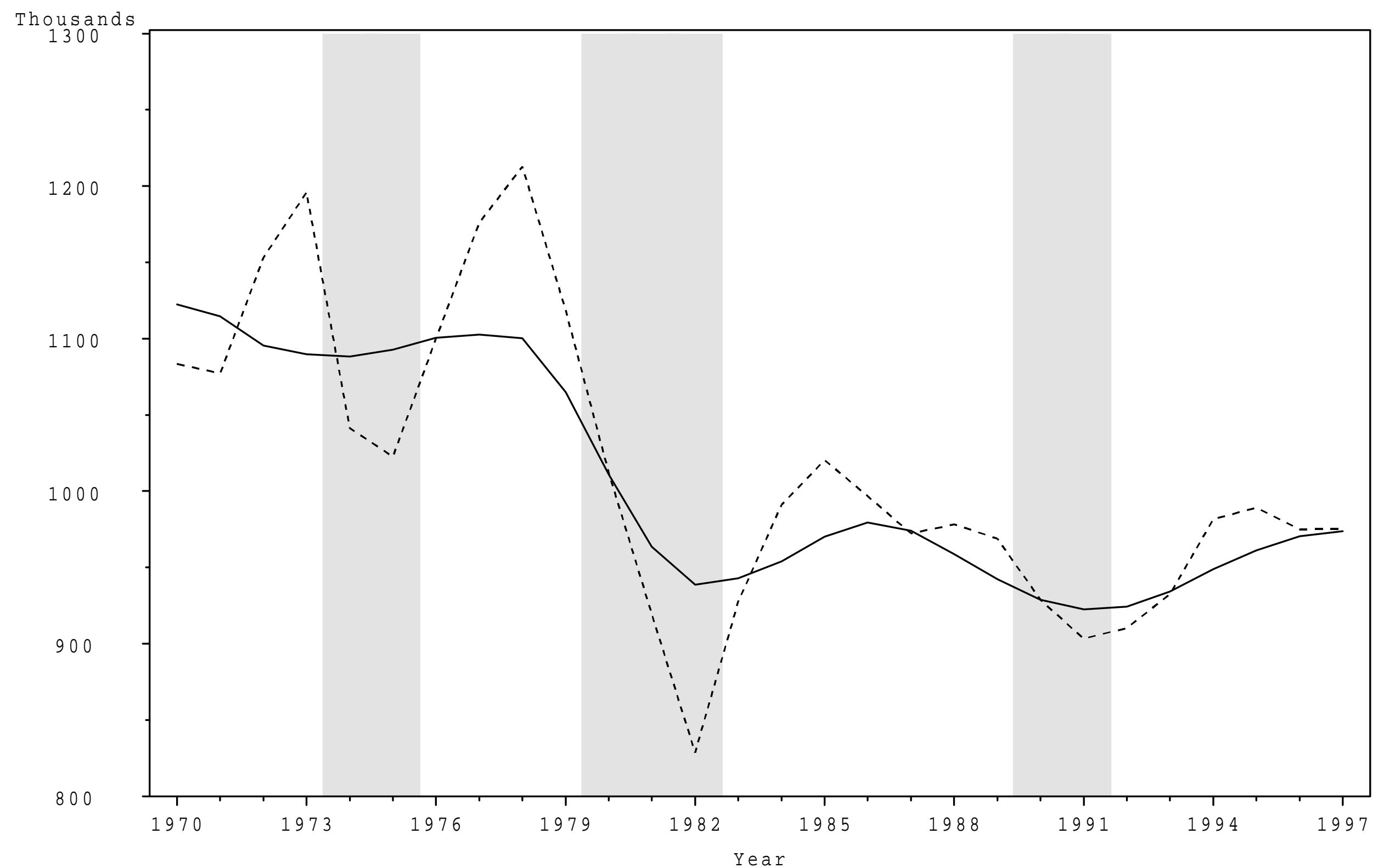

The solid line is permanent manufacturing employment. The dashed line is total manufacturing employment. Gray regions are years with NBER recession quarters. 


\section{Figure 2. Permanent and Temporary Job Flows}

Job Destruction
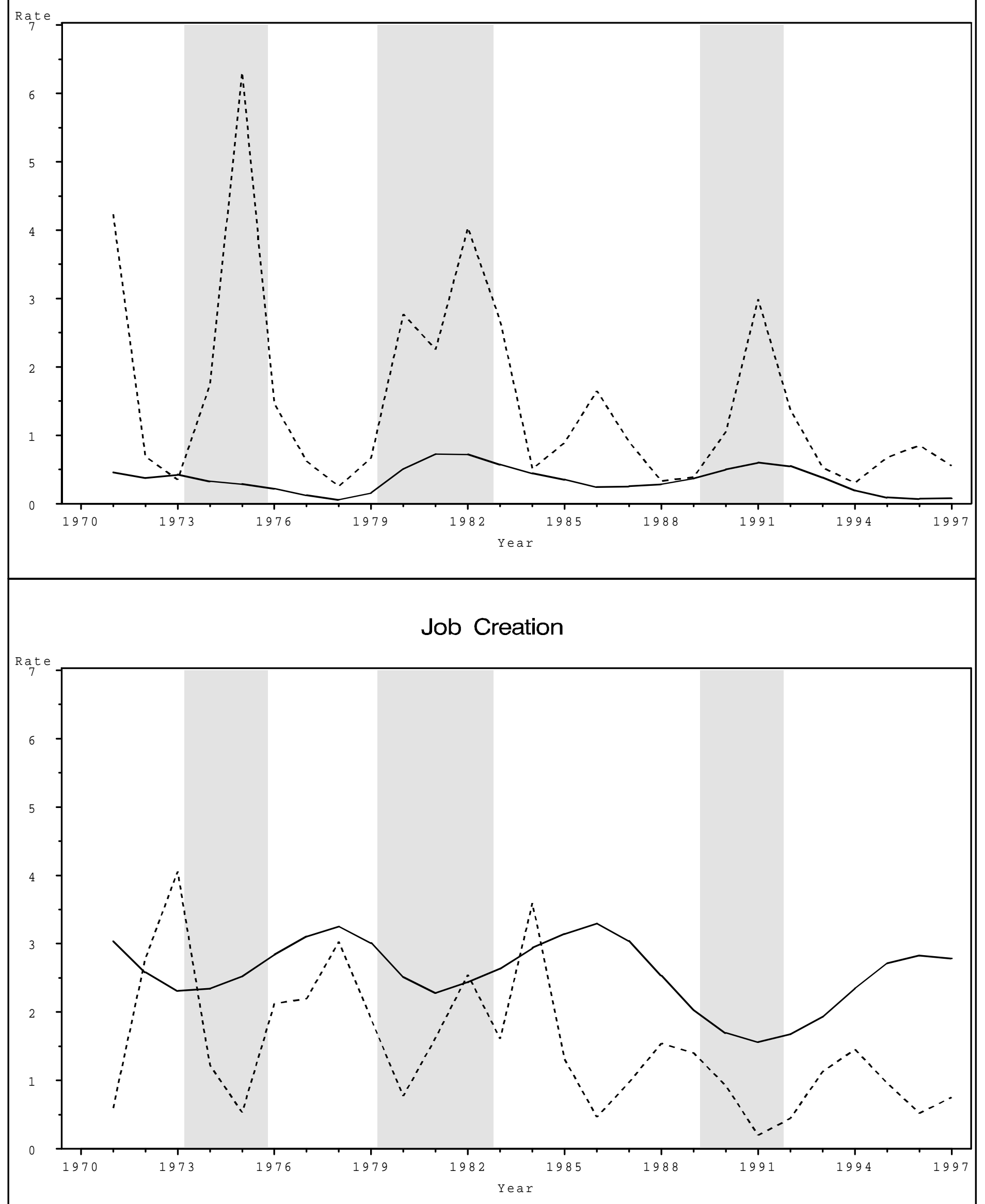

The solid lines are permanent job flows. The dashed lines are temporary job flows. Gray regions are years with NBER recession quarters. 


\section{Figure 3. Unemployment and Counterfactual Unemployment \\ Michigan}

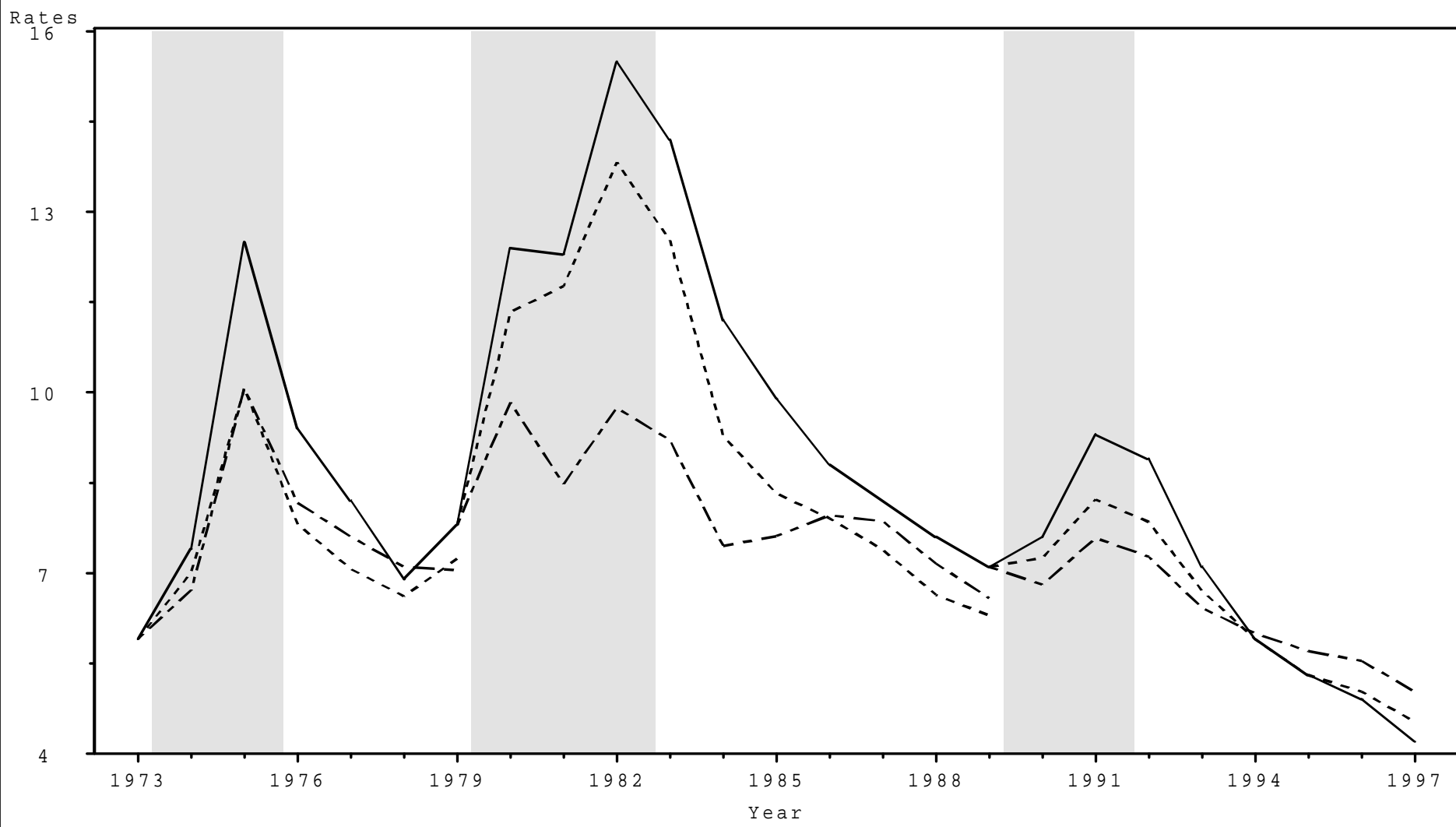

California

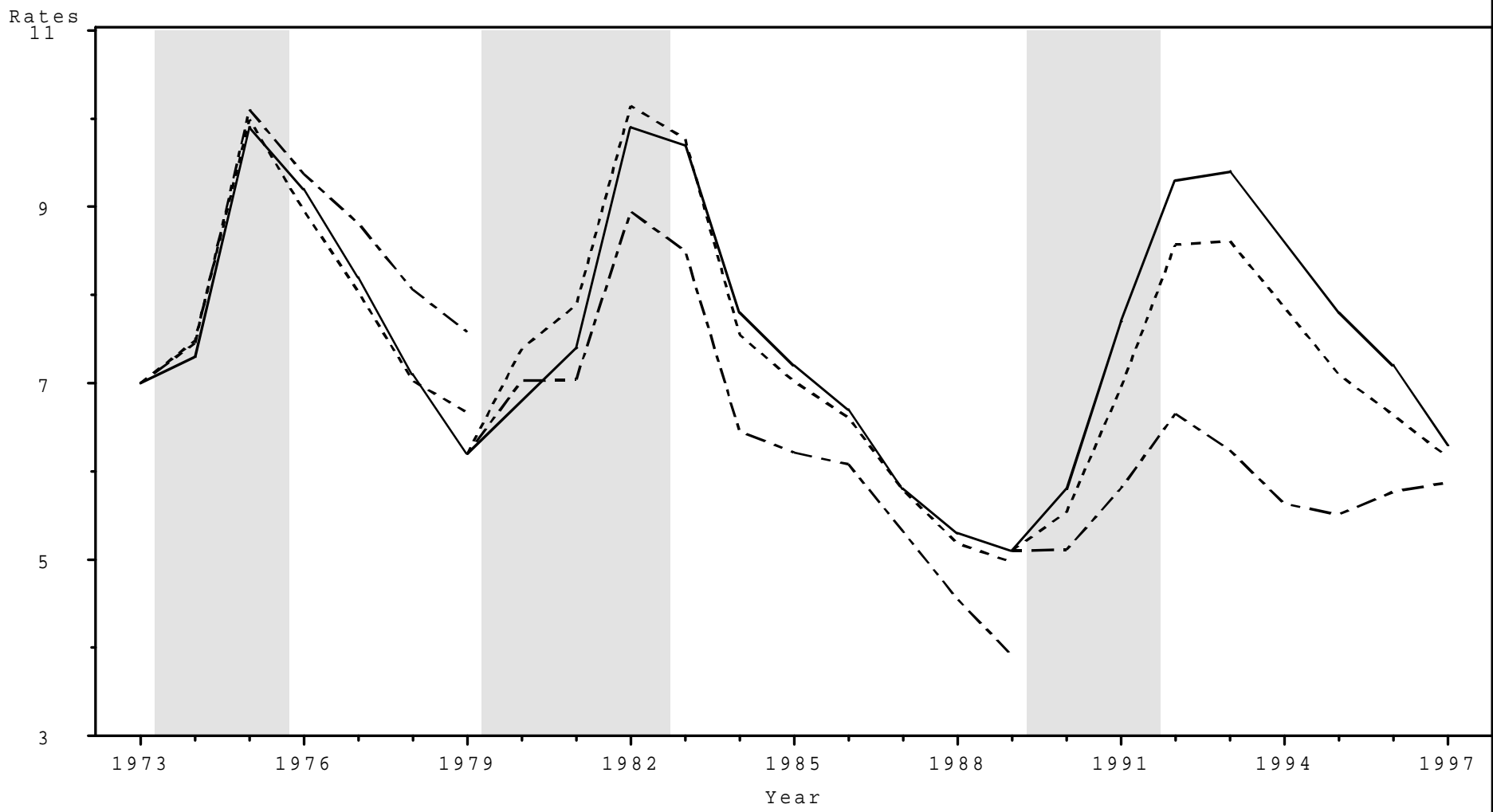

The solid line is the actual unemployment rate. The dashed line is predicted unemployment. The dot-dashed line is counterfactual unemployment Gray regions are periods with NBER recession quarters. 
Figure 4

\section{Unemployment and Counterfactual Unemployment}

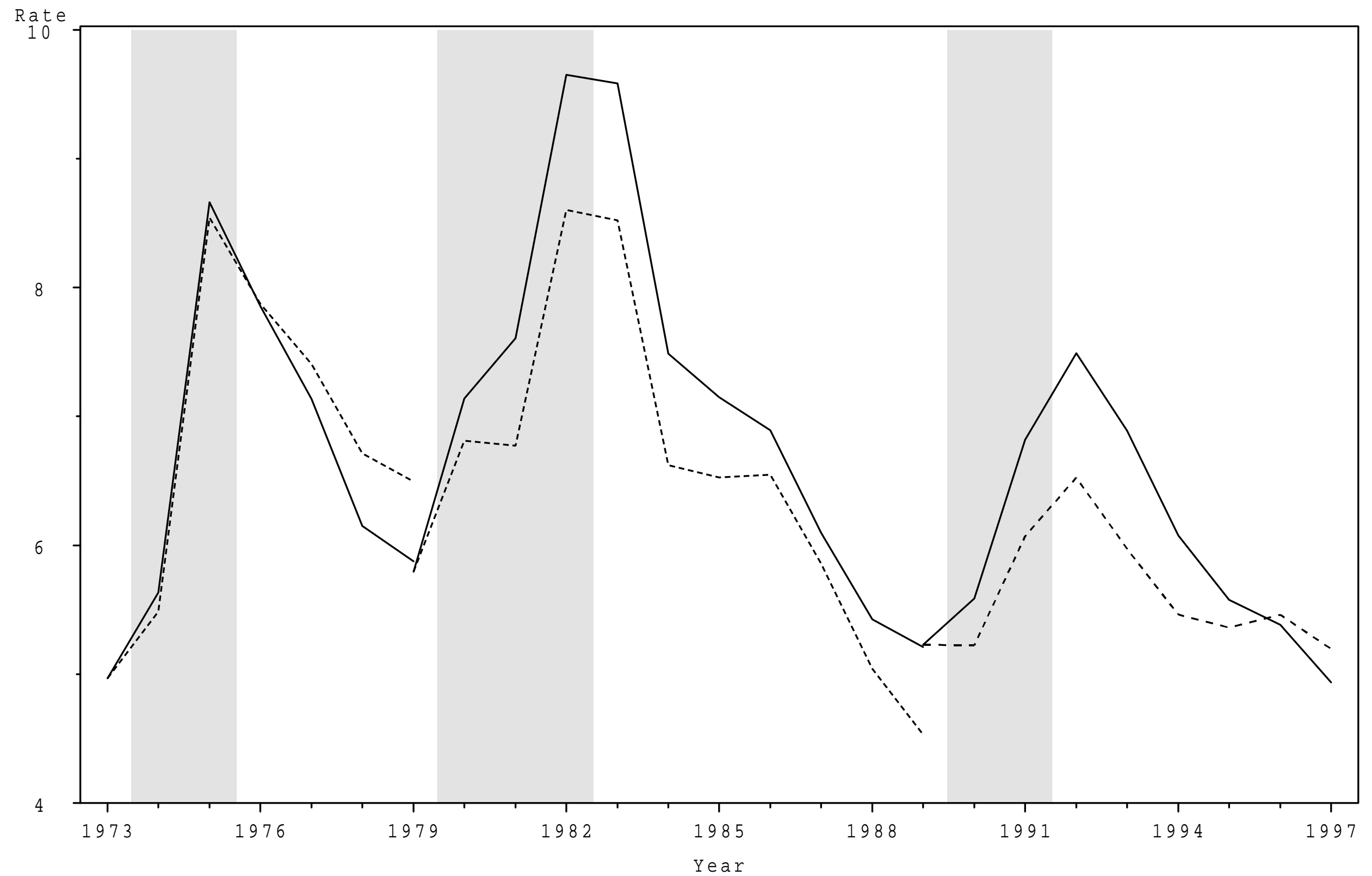

The solid line is the predicted unemployment rate. The dashed line is counterfactual unemployment. Simulations jump off of 1973,1979 , and 1989 . Gray regions are years with NBER recession quarters. 